\title{
Short- and long-term haemodynamic consequences of transcatheter closure of atrial septal defect and patent foramen ovale
}

\author{
X. Jin · Y. M. Hummel · W. T. Tay · J. F. Nauta · N. S. S. Bamadhaj · J. P. van Melle · C. S. P. Lam · A. A. Voors · \\ E. S. Hoendermis
}

Accepted: 25 January 2021 / Published online: 16 February 2021

(C) The Author(s) 2021

\begin{abstract}
Background Transcatheter atrial septal defect (ASD) and patent foramen ovale (PFO) closure might have opposite short- and long-term haemodynamic consequences compared with restricted interatrial shunt creation, which recently emerged as a potential treatment modality for patients with heart failure with preserved ejection fraction (HFpEF). Given the opposing approaches of ASD and PFO closure versus shunt creation, we investigated the early and sustained cardiac structural and functional changes following transcatheter ASD or PFO closure.

Methods In this retrospective study, adult secundumtype ASD and PFO patients with complete echocardiography examinations at baseline and at 1-day and 1-year follow-up who also underwent transcatheter closure between 2013 and 2017 at the University Medical Centre Groningen, the Netherlands were included. Results Thirty-nine patients (mean age $48 \pm$ standard deviation 16 years, $61.5 \%$ women) were included. Transcatheter ASD/PFO closure resulted in an early and persistent decrease in right ventricular systolic and diastolic function. Additionally, transcatheter
\end{abstract}

\footnotetext{
Supplementary Information The online version of this article (https://doi.org/10.1007/s12471-021-01543-0) contains supplementary material, which is available to authorized users.

X. Jin · W. T. Tay · N. S. S. Bamadhaj · C. S. P. Lam

National Heart Centre Singapore, Singapore, Singapore

X. Jin · Y. M. Hummel · J. F. Nauta · J. P. van Melle ·

C. S. P. Lam · A. A. Voors · E. S. Hoendermis $(\bowtie)$

Department of Cardiology, University of Groningen,

University Medical Centre Groningen, Groningen, The

Netherlands

e.s.hoendermis@umcg.nl

C. S. P. Lam

Duke-NUS Medical School, Singapore, Singapore
}

ASD/PFO closure resulted in an early and sustained favourable response of left ventricular (LV) systolic function, but also in deterioration of LV diastolic function with an increase in LV filling pressure (LVFP), as assessed by echocardiography. Age $(\beta=0.31, p=0.009)$ and atrial fibrillation (AF; $\beta=0.24, p=0.03$ ) were associated with a sustained increase in LVFP after transcatheter ASD/PFO closure estimated by mean E/e' ratio (i.e. ratio of mitral peak velocity of early filling to diastolic mitral annular velocity). In subgroup analysis, this was similar for ASD and PFO closure. Conclusion Older patients and patients with AF were predisposed to sustained increases in left-sided filling pressures resembling $\mathrm{HFpEF}$ following ASD or PFO closure. Consequently, these findings support the current concept that creating a restricted interatrial shunt might be beneficial, particularly in elderly HFpEF patients with AF.

\section{What's new?}

- In this study, transcatheter closure of an atrial septal defect (ASD) or a patent foramen ovale (PFO) resulted in an early and sustained increase in left ventricular (LV) filling pressure, as assessed by echocardiography.

- Older patients with ASD or PFO and patients with atrial fibrillation were predisposed to sustained increases in LV filling pressure resembling heart failure with preserved ejection fraction (HFpEF) following interatrial shunt closure.

- The findings of the present study support the current concept that creating a restricted interatrial shunt in patients with HFpEF might result in acute and sustained improvement in LV diastolic dysfunction and a decrease in LV filling pressures. 
Keywords ASD · HFpEF · Echocardiography · LVFP

\section{Introduction}

Atrial septal defect (ASD) is one of the most common adult congenital heart diseases, and the chronic left-to-right atrial shunt might eventually lead to the development of pulmonary arterial hypertension, arrhythmia and heart failure [1]. ASD closure is indicated at all ages, and closure of small ASDs and PFO can be indicated in cases of cryptogenic strokes or in divers with decompression illness [2]. However, older age at closure, male sex, comorbidities such as hypertension, diabetes mellitus and atrial fibrillation (AF), and larger ASDs may predispose to worse outcomes despite ASD closure [3-7].

Recently, the artificial creation of a restricted interatrial shunt with a transcatheter device has emerged as a potential treatment modality for patients with heart failure with preserved ejection fraction ( $\mathrm{HFpEF}$ ) by means of reducing left atrial (LA) pressure [8]. Given the opposing approaches of ASD/PFO closure versus creation, as well as overlapping risk factors for HF$\mathrm{pEF}$ and worse prognosis of transcatheter ASD closure, we hypothesised that some patients undergoing ASD/PFO closure may display haemodynamic characteristics resembling HFpEF. We aimed to test this hypothesis by investigating the early and sustained cardiac structural and functional changes following transcatheter ASD/PFO closure using sequential echocardiograms and their clinical correlates.

\section{Methods}

This retrospective study recruited adult patients (age $>18$ years) who underwent transcatheter ASD/PFO closure with comprehensive echocardiographic datasets between 2013 and 2017 at the University Medical
Centre Groningen, the Netherlands. Transcatheter ASD/PFO closure was indicated following the guidelines of the European Society of Cardiology (ESC) and the Netherlands Society of Cardiology [9]. Among the 68 recruited patients 39 patients with transcatheter ASD/PFO closure were included in the present analyses after excluding 29 patients due to unavailability of baseline echocardiography $(n=19)$, surgical approach transition $(n=7)$ or technical reasons $(n=3)$. The study flow chart is presented in Fig. 1 . Of the 39 patients, 28 had a large ASD, and 11 had an ASD $<1 \mathrm{~cm}$ or a PFO, both with cryptogenic strokes as indication for closure. This study was conducted in accordance with local and national laws and regulations regarding retrospective research on clinical data, as verified and confirmed by the institutional review board of the University Medical Centre Groningen.

Transcatheter ASD closure was performed using the Amplatzer Septal Occluder or PFO occluder (St. Jude Medical, St. Paul, MN, USA) or the Figulla ASD Occluder or PFO occluder (Occlutech $\mathrm{GmbH}$, Jena, Germany), under general anaesthesia and guidance of intraprocedural transoesophageal echocardiography. Before closure, mean right atrial (RA) pressure, mean LA pressure, mean pulmonary arterial pressure, pulmonary capillary wedge pressure and ratio of total pulmonary blood flow to total systemic blood flow (Qp/Qs ratio) were obtained using a Swan-Ganz catheter, and all measurements were recorded at end expiration based on average of five cardiac cycles.

Comprehensive transthoracic echocardiography (GE Vivid-7 or Vivid-E9, General Electric, Horten, Norway) and all offline measurements including twodimensional speckle-tracking echocardiography analysis were performed following the ESC guideline [10], at baseline, at 1-day follow-up and within 1 year of follow-up, respectively. Right ventricular (RV) global longitudinal strain (GLS), RA reservoir GLS,

Fig. 1 Flowchart illustrating enrolment process of study participants. $A S D$ II secundum-type atrial septal defect, PFO patent foramen ovale, TTE transthoracic echocardiography

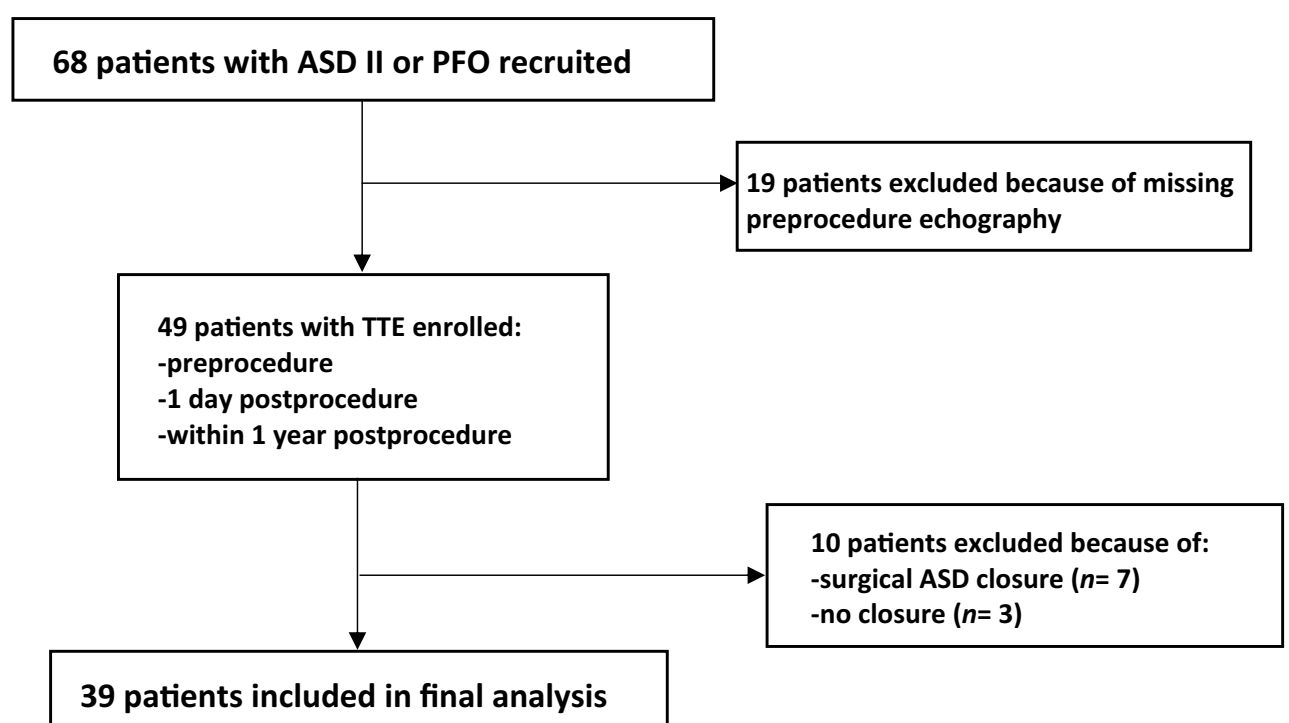


left ventricular (LV) GLS and LA reservoir GLS were all measured based on recommended guideline [10]. RV systolic function parameters included RVGLS, systolic tissue velocity of the lateral tricuspid annulus, tricuspid annular plane systolic excursion, and RV fractional area change. RV diastolic function parameters included RA volume index, RA reservoir GLS, diastolic tissue velocity of the lateral tricuspid annulus, and RV isovolumic relaxation time.

Pulmonary artery systolic pressure was estimated using Bernoulli's equation of peak tricuspid regurgitant velocity and RA pressure estimation, based on the size and collapsibility of the inferior vena cava [10]. LV systolic function parameters were LV ejection fraction (LVEF), which was assessed by biplane method, and LVGLS. LV diastolic function parameters were mitral inflow, annular velocity and transmitral to averaged septal and lateral annular early diastolic velocity ratio (E/e' ratio), LA volume index and LA reservoir GLS.

\section{Statistical analysis}

Continuous variables are presented as mean \pm standard deviation (SD) or as median with range. Categorical variables are expressed as frequency and percentage. Differences in echocardiographic characteristics between baseline versus 1-day or 1-year follow-up were compared using a paired $t$-test.

A linear regression model was used to evaluate the association between clinical risk factors of HFpEF and cardiac functional changes assessed by echocardiography. A multivariable model was created by including all variables in the univariable analysis. Stratified analysis was performed for the significant echocardiographic changes at 1-day and 1-year follow-up after transcatheter closure by ASD versus PFO. $P$ values $\leq 0.05$ were considered statistically significant.

All data analyses were performed using SPSS, version 22.0 (SPSS, Chicago, IL, USA).

\section{Results}

The mean age of patients included $(n=39)$ was $48 \pm 16$ years, and $61.5 \%$ were women. Among all patients, $28(72 \%)$ had a large ASD with RV volume overload, $12(30.7 \%)$ had a history of hypertension, $9(23.7 \%)$ had a history of AF and $2(5.1 \%)$ had a history of diabetes mellitus.

Tab. 1 summarises demographic characteristics and invasive haemodynamic data at baseline in ASD and PFO patients. Median ASD and PFO size with invasive balloon sizing was 17.1 and $11.8 \mathrm{~mm}$, respectively. Median device size for ASD (waist) and PFO (RA disc) was $20 \mathrm{~mm}$ and $28.7 \mathrm{~mm}$, respectively. Mean Qp/Qs ratio was 2.0 in patients with ASD. Mean LA pressure was $7.1 \mathrm{~mm} \mathrm{Hg}$ in ASD patients and $6.8 \mathrm{~mm} \mathrm{Hg}$ in PFO patients. Mean pulmonary arterial pressure was 16.9 versus $13.4 \mathrm{~mm} \mathrm{Hg}$ in ASD and PFO patients, respectively. There were no major complications of the procedures,
Table 1 Clinical and invasive haemodynamic characteristics at baseline in patients with ASD or PFO

\begin{tabular}{|c|c|c|}
\hline Variable & $\operatorname{ASD}(n=28)$ & PF0 $(n=11)$ \\
\hline Age, years & $48 \pm 16$ & $45 \pm 17$ \\
\hline Women & $15(53.5)$ & $9(81.8)$ \\
\hline BMI, $\mathrm{kg} / \mathrm{m}^{2}$ & $26.9 \pm 4.1$ & $24.1 \pm 3.2$ \\
\hline Hypertension & $9(32.1)$ & $3(27.7)$ \\
\hline Hyperlipidaemia & $3(10.7)$ & $1(9.1)$ \\
\hline Diabetes mellitus & $2(7.1)$ & 0 \\
\hline Atrial fibrillation & $7(25)$ & $2(18.1)$ \\
\hline Coronary artery disease & $3(10.7)$ & 0 \\
\hline ASD size with balloon sizing, mm & $17.1(7-25)$ & NA \\
\hline ASD device size (waist), mm & $20(10-35)$ & NA \\
\hline PF0 size with balloon sizing, mm & NA & $11.8(5-19)$ \\
\hline PF0 device size (right atrial disc), mm & NA & $28.7(25-31)$ \\
\hline Qp/Qs ratio & $2.0 \pm 0.6$ & NA \\
\hline Mean pulmonary arterial pressure, $\mathrm{mm} \mathrm{Hg}$ & $16.9 \pm 4.3$ & $13.4 \pm 5.0$ \\
\hline Mean left atrial pressure, $\mathrm{mm} \mathrm{Hg}$ & $7.1 \pm 2.4$ & $6.8 \pm 2.1$ \\
\hline Mean right atrial pressure, $\mathrm{mm} \mathrm{Hg}$ & $6.4 \pm 2.6$ & $3.6 \pm 1.7$ \\
\hline \multicolumn{3}{|c|}{$\begin{array}{l}\text { Data are } n(\%), \text { mean } \pm \text { standard deviation, or median (range) } \\
\text { ASD atrial septal defect, } P F O \text { patent foramen ovale, } B M I \text { body mass index, } \\
Q p / Q \text { s ratio ratio of total pulmonary blood flow to total systemic blood flow, } \\
N A \text { not applicable }\end{array}$} \\
\hline
\end{tabular}

and none of the patients showed signs of pulmonary hypertension within 1-year echocardiography followup. The mean follow-up time was $8 \pm 3$ months.

Tab. 2 demonstrates the longitudinal changes of echocardiographic parameters (mean \pm SD) following transcatheter ASD/PFO closure in all included patients. Notably, transcatheter ASD/PFO closure resulted in an early and sustained reduction of RV dimensions, an early increase in LV systolic function and a stepwise increase in LV dimensions/mass. Transcatheter ASD/PFO closure resulted in an early and persistent decrease in RV systolic and diastolic function and in deterioration of LV diastolic function. Following transcatheter ASD/PFO closure, there were no significant early or sustained changes in pulmonary artery systolic pressure. Fig. 2 summarises the early and sustained cardiac remodelling and functional changes following transcatheter ASD/PFO closure we found.

Following transcatheter ASD/PFO closure, RV basal diameter was significantly reduced at 1-day followup $(37.9 \pm 7.8$ vs $40.5 \pm 8.6 \mathrm{~mm}$ at baseline, $p=0.01)$, a change that persisted at 1-year follow-up (37.6 \pm $6.9 \mathrm{~mm}, p=0.04$ for difference with baseline). Additionally, RA volume index showed a significant reduction at 1 -day follow-up $\left(47.4 \pm 25.9\right.$ vs $58.7 \pm 35.8 \mathrm{~mL} / \mathrm{m}^{2}$ at baseline, $p=0.04$ ) and at 1 -year follow-up (44.1 \pm $19.7 \mathrm{~mL} / \mathrm{m}^{2}, p=0.02$ for difference with baseline).

Irrespective of reduction in RV or RA dimension due to shunt closure, transcatheter ASD/PFO closure resulted in an early and continuous decrease in RV systolic and diastolic function. As for RV systolic functional assessments, RVGLS showed a significant decrease in the absolute value at 1-day follow-up 
Table 2 Echocardiographic characteristics at baseline, at day 1 and within 1 year following transcatheter ASD/PFO closure

\begin{tabular}{|c|c|c|c|c|}
\hline Variable & Baseline & Day 1 & Within 1 year & $\begin{array}{l}P \text { interaction for } \\
\text { ASD vs PFO }\end{array}$ \\
\hline \multicolumn{5}{|c|}{ Right ventricular systolic function } \\
\hline RVGLS, \% & $-20.7 \pm 3.1$ & $-18.5 \pm 4.6^{a}$ & $-17.9 \pm 6.9$ & - \\
\hline $\begin{array}{l}\text { RV TDI s', } \\
\mathrm{cm} / \mathrm{s}\end{array}$ & $14.3 \pm 2.3$ & $13.4 \pm 2.1$ & $12.7 \pm 2.8^{b}$ & 0.30 \\
\hline TAPSE, mm & $24.4 \pm 5.6$ & $23.7 \pm 4.7$ & $23.1 \pm 4.5$ & 0.36 \\
\hline RVFAC, $\%$ & $40.4 \pm 7.5$ & $41.5 \pm 6.8$ & $39.7 \pm 6.7$ & - \\
\hline \multicolumn{5}{|c|}{ Right ventricular diastolic function } \\
\hline RV-IVRT, ms & $61.8 \pm 21.9$ & $61.8 \pm 18.8$ & $72.8 \pm 23.6^{b}$ & 0.26 \\
\hline $\mathrm{RAVi}, \mathrm{mL} / \mathrm{m}^{2}$ & $58.7 \pm 35.8$ & $47.4 \pm 25.9^{a}$ & $44.1 \pm 19.7^{b}$ & 0.44 \\
\hline $\begin{array}{l}\text { RA reservoir } \\
\text { GLS, } \%\end{array}$ & $36.9 \pm 14.6$ & $31.4 \pm 13.2^{\mathrm{a}}$ & $30.4 \pm 13.4^{b}$ & 0.42 \\
\hline \multicolumn{5}{|c|}{ Left ventricular systolic function } \\
\hline $\begin{array}{l}\text { LVEF (bi- } \\
\text { plane), \% }\end{array}$ & $54.0 \pm 7.0$ & $56.7 \pm 8.6^{\mathrm{a}}$ & $55.1 \pm 7.3$ & 0.88 \\
\hline $\begin{array}{l}\text { Stroke vol- } \\
\text { ume, mL }\end{array}$ & $54.0 \pm 7.0$ & $56.7 \pm 8.6$ & $58.03 \pm 16.3$ & - \\
\hline LVGLS, \% & $-15.7 \pm 3.1$ & $-15.8 \pm 2.9$ & $-16.0 \pm 3.2$ & 0.31 \\
\hline \multicolumn{5}{|c|}{ Left ventricular diastolic function } \\
\hline MV E/A & $1.4 \pm 0.8$ & $1.5 \pm 1.3$ & $1.4 \pm 0.5$ & - \\
\hline E/e' ratio & $6.3 \pm 2.0$ & $7.3 \pm 3.2^{\mathrm{a}}$ & $6.8 \pm 1.8$ & 0.76 \\
\hline LAVi, $\mathrm{mL} / \mathrm{m}^{2}$ & $29.6 \pm 12.4$ & $29.9 \pm 11.2$ & $34.5 \pm 13.9^{b}$ & 0.89 \\
\hline $\begin{array}{l}\text { LA reservoir } \\
\text { GLS, \% }\end{array}$ & $32.8 \pm 13.9$ & $26.7 \pm 9.9^{\mathrm{a}}$ & $26.7 \pm 10.7^{b}$ & 0.79 \\
\hline \multicolumn{5}{|c|}{ Cardiac dimensions and Doppler parameters } \\
\hline LVIDd, mm & $48.0 \pm 5.7$ & $48.3 \pm 5.0$ & $50.0 \pm 4.5^{b}$ & - \\
\hline LVIDs, mm & $34.3 \pm 5.7$ & $33.9 \pm 4.9$ & $35.1 \pm 5.0$ & - \\
\hline LVMi, g/m² & $72.9 \pm 16.9$ & $74.4 \pm 14.7$ & $81.7 \pm 17.1^{b}$ & - \\
\hline $\begin{array}{l}\text { RV basal } \\
\text { diameter, } \mathrm{mm}\end{array}$ & $40.5 \pm 8.6$ & $37.9 \pm 7.8^{\mathrm{a}}$ & $37.6 \pm 6.9^{b}$ & - \\
\hline LA area, $\mathrm{cm}^{2}$ & $21.8 \pm 18.0$ & $18.9 \pm 3.57$ & $20.5 \pm 4.9$ & - \\
\hline $\mathrm{RA}$ area, $\mathrm{cm}^{2}$ & $18.3 \pm 6.0$ & $16.7 \pm 5.8^{a}$ & $16.0 \pm 4.7^{b}$ & - \\
\hline $\begin{array}{l}\text { TR velocity, } \\
\mathrm{m} / \mathrm{s}\end{array}$ & $2.1 \pm 0.8$ & $2.3 \pm 0.8$ & $2.2 \pm 0.7$ & - \\
\hline PASP, $\mathrm{mm} \mathrm{Hg}$ & $20.7 \pm 12.3$ & $23.4 \pm 15.1$ & $21.6 \pm 11.7$ & - \\
\hline \multicolumn{5}{|c|}{$\begin{array}{l}\text { Data are mean } \pm \text { standard deviation } \\
T-A S D \text { transcatheter atrial septal defect, } P F O \text { patent foramen ovale, } \\
R V G L S \text { right ventricular global longitudinal strain, } R V T D I S^{\prime} \text { peak systolic } \\
\text { velocity of tricuspid annulus by tissue Doppler imaging, TAPSE tricuspid } \\
\text { annular plane systolic excursion, } R V F A C \text { right ventricular fractional area } \\
\text { change, } R V \text {-IVRT right ventricular isovolumic relaxation time, } R A V i \text { right atrial } \\
\text { volume index, GLS global longitudinal strain, } L V E F \text { left ventricular ejection } \\
\text { fraction, } L V G L S \text { left ventricular global longitudinal strain, MVE/A mitral valve } \\
\text { E velocity divided by A velocity, E/e' ratio ratio of mitral peak velocity of early } \\
\text { filling to diastolic mitral annular velocity, } L A V i \text { left ventricular volume index, } \\
\angle A \text { left atrial, } L V I D d \text { left ventricular internal diameter in diastole, } L V I D s \text { left } \\
\text { ventricular internal diameter in systole, } L V M i \text { left ventricular mass index, } T R \\
\text { velocity tricuspid regurgitant peak velocity, PASP pulmonary artery systolic } \\
\text { pressure } \\
\text { a } P<0.05 \text { between baseline and 1-day follow-up } \\
\text { b } P<0.05 \text { between baseline and 1-year follow-up }\end{array}$} \\
\hline
\end{tabular}

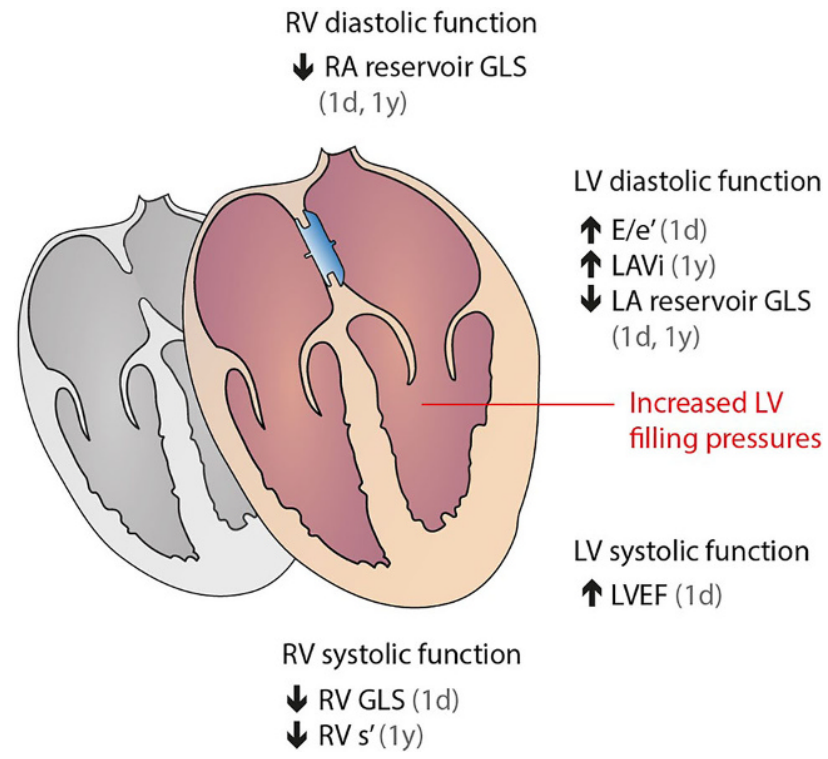

Fig. 2 Early and sustained cardiac remodelling and functional changes following transcatheter atrial septal defect or patent foramen ovale closure. $R V$ right ventricular, $R A$ right atrial, $L V$ left ventricular, $L A$ left atrial, GLS global longitudinal strain, E/e' ratio of mitral peak velocity of early filling to diastolic mitral annular velocity, LAVi left ventricular volume index, $L V E F$ left ventricular ejection fraction, $R V s^{\prime}$ systolic tissue velocity of the lateral tricuspid annulus

$(-18.5 \pm 4.6$ vs $-20.6 \pm 3.1 \%, p=0.01)$, and this trend remained at 1 -year follow-up $(-17.9 \pm 6.9 \%, p=0.05$ for difference with baseline). Systolic tissue velocity of the lateral tricuspid annulus also showed a significant and sustained decrease at 1-year follow-up compared with baseline $(12.7 \pm 2.8$ vs $14.3 \pm 2.3 \mathrm{~cm} / \mathrm{s}$, $p=0.003$ ). RA reservoir GLS (as a measurement of RV diastolic function) was significantly decreased at 1-day follow-up $(31.4 \pm 13.2$ vs $36.9 \pm 14.6 \%, p=0.02)$ and remained significantly lowered at 1-year followup $(30.4 \pm 13.4 \%, p=0.03$ for difference with baseline). Moreover, RV isovolumic relaxation time also showed a significant increase within 1 year after transcatheter ASD/PFO closure compared with baseline, in all suggesting a sustained decline in RV diastolic function after closure.

LV systolic function showed early improvement (LVEF $54.0 \pm 7.0$ at baseline vs $56.7 \pm 8.6$ at 1 -day follow-up, $p=0.04$ ). We also found a stepwise increase between baseline and at 1 year in LV internal diameter in diastole (from $48.0 \pm 5.7$ to $50.0 \pm 4.5 \mathrm{~mm}$, $p=0.008$ ) and in LV mass index (from $72.9 \pm 16.9 \mathrm{~g}$ to $\left.81.7 \pm 17.1 \mathrm{~g} / \mathrm{m}^{2}, p<0.001\right)$.

LVFP showed an early and sustained increase. Mean E/e' ratio significantly increased from $6.3 \pm$ $2.0 \mathrm{~cm} / \mathrm{s}$ at baseline to $7.3 \pm 3.2$ at 1 day $(p=0.003)$, and LA volume index significantly increased from $29.6 \pm 12.4 \mathrm{~mL} / \mathrm{m}^{2}$ at baseline to $34.5 \pm 13.9 \mathrm{~mL} / \mathrm{m}^{2}$ at 1 year $(p=0.04)$. LA reservoir GLS significantly decreased from $32.8 \pm 13.9 \%$ at baseline to $26.7 \pm 9.9 \%$ at 1 day $(p=0.006)$ and to $26.7 \pm 10.7 \%$ at 1 year $(p=0.01)$. 
In stratified analyses by large ASD versus small ASD/PFO (Tab. 2), cardiac structural and functional changes, including left- and right-sided systolic and diastolic function, after transcatheter closure at 1-day and 1-year follow-up were directionally similar in both groups. Tabs. 3 and 4 in the Electronic Supplementary Material demonstrate longitudinal changes of echocardiographic parameters following transcatheter ASD and PFO closure, respectively. Changes in LA reservoir GLS, RA reservoir GLS and systolic tissue velocity of the lateral tricuspid annulus did not reach statistical significance in patients with small ASD/PFO at 1-year follow-up after transcatheter closure, likely due to the small sample size.

Furthermore, the presence of AF at enrolment and ASD size were significantly associated with sustained changes of LA volume index (AF: $\beta=0.52, p=0.005$; ASD size: $\beta=0.48, p=0.01$ ) and LA reservoir GLS (AF: $\beta=-0.48, p<0.01$; ASD size: $\beta=-0.95, p<0.01$ ) in univariable analysis. Notably, age $(\beta=0.31, p=0.009)$ and $\mathrm{AF}(\beta=0.24, p=0.03)$ remained significantly associated with sustained changes of E/e' ratio in multivariable models after adjusting for baseline mean $\mathrm{E} / \mathrm{e}$ ' ratio, sex, hypertension and ASD size (Tab. 5 in Electronic Supplementary Material).

\section{Discussion}

In this study, we demonstrated early and sustained cardiac remodelling and functional changes following transcatheter ASD/PFO closure. In terms of structural changes, transcatheter $\mathrm{ASD} / \mathrm{PFO}$ closure resulted in decreased RV and RA sizes and increased LV and LA sizes. In terms of functional changes, we found an acute and persistent decline in right heart function, with a parallel decline in both RV systolic and diastolic function. On the left side, transcatheter ASD/PFO closure resulted in early and sustained improvement in LV systolic function, but also in deterioration of LV diastolic function with an increase in echo-estimated LV filling pressure. The continuous increase in LV filling pressure was associated with older age and presence of AF, but not with ASD size, ASD versus PFO, sex or hypertension.

Focusing on right heart changes following transcatheter ASD/PFO closure, our results are consistent with those of some, but not all prior studies [4, 11-14]. Similar to our findings, Stephensen et al. saw an acute decline in RV ejection fraction (RVEF) at day 1 following transcatheter ASD closure, which remained a decreasing trend till 12 months of follow-up [12]. On the contrary, Schoen et al. found improvement in RVEF by MRI in association with a reduction in RV systolic pressure [13]. We postulate that these divergent results are due to differences in study populations with respect to RV afterload. ASD closure is expected to normalise RV volume overload and thereby relieve the RV from its compensatory increase in RVEF to cope with the additional shunt volume.
In the absence of significant pulmonary hypertension, a reduction in RV volume with ASD closure may therefore be associated with a reduction in RVEF or RV systolic strain, albeit still within the normal range, as observed in our study and others [11]. Interestingly, in our study, RV functional changes after transcatheter closure were similar in ASD patients (with RV volume load) and PFO patients (without RV volume load) after subgroup analysis, suggesting RV adaptation following transcatheter ASD/PFO closure is a complicated process that is affected by more than volume overload and pressure afterload.

Conversely, from the standpoint of interatrial shunt creation in HFpEF, although it is as restrictive as a PFO, there is concern that the additional RV volume from the shunt may tip the right heart into failure, particularly in the presence of pulmonary hypertension from HFpEF itself. Furthermore, LV underfilling may occur following interatrial shunting from left to right. Notably, recent studies of interatrial shunt device in HFpEF have not reported these adverse effects, although it is important to bear in mind the strict inclusion and exclusion criteria applied in these trials (excluding significant pulmonary hypertension or RV failure), the restricted size of the iatrogenic PFO and the limited follow-up of patients receiving this relatively new treatment $[8,15-20]$.

With regard to left-sided filling pressures, our findings regarding changes in LV diastolic function following ASD closure are consistent with those of prior studies. Ewert et al. found that transcatheter ASD closure in the elderly is associated with an increase in LVFP and subsequent congestive heart failure due to masked underlying LV diastolic dysfunction [21, 22]. We extended the prior data by including echo-tissue Doppler and strain measurements of LV and LA function. The E/e' ratio is a widely accepted surrogate for LVFP estimation and proved to be associated with both haemodynamics and prognosis in patients with HFpEF [23, 24].

Likewise, LA reservoir GLS, as an additional reflection of LA myocardial compliance, emerged as a promising noninvasive surrogate for LVFP estimation [25]. Prior studies have shown an acute increase in LVFP, estimated as E/e' ratio [26, 27], which is consistent with our results. Furthermore, the current study, in which we used a combination of mean E/e' ratio, LA volume index and LA reservoir GLS, demonstrated that transcatheter ASD/PFO closure resulted in both an acute and sustained increase in LVFP. In addition, we found that older age and the presence of AF were independently related to sustained increases in LVFP. The important influence of age at ASD closure on changes in LVFP has been shown before; however, the influence of AF has not been extensively studied to date. 


\section{Limitations}

The major limitation of our study is the relatively small sample size, although we included consecutive patients with ASD and PFO undergoing transcatheter ASD closure with full echocardiographic datasets of diastolic function up to 1 year. The age difference between the current population and much elderly HFpEF patients is also a limitation to be speculated about. The current study results might underestimate iatrogenic ASD creation in much elderly HFpEF patients. We acknowledge that absolute changes were small and of uncertain clinical significance. Nonetheless, this is one of the first studies to comprehensively assess patients with strain echocardiography before and after ASD closure, and our findings may carry implications for the propensity to develop HFpEF after ASD or PFO closure or, conversely, the propensity to benefit from iatrogenic ASD creation in HFpEF.

\section{Conclusion}

Older patients and AF patients are predisposed to sustained increases in left-sided filling pressures following ASD or PFO closure. These findings support the concept that elderly HFpEF patients with AF in particular might benefit from the artificial creation of an atrial left-to-right shunt.

Conflict of interest C.S.P. Lam is supported by a Clinician Scientist Award from the National Medical Research Council of Singapore; has received research support from Boston Scientific, Bayer, Roche Diagnostics, AstraZeneca, Medtronic, and Vifor Pharma; has served as consultant or on the Advisory Board/Steering Committee/Executive Committee for Abbott Diagnostics, Amgen, Applied Therapeutics, AstraZeneca, Bayer, Biofourmis, Boehringer Ingelheim, Boston Scientific, Corvia Medical, Cytokinetics, Darma Inc., Us2.ai, JanaCare, Janssen Research \& Development LLC, Medtronic, Menarini Group, Merck, MyoKardia, Novartis, Novo Nordisk, Radcliffe Group Ltd., Roche Diagnostics, Sanofi, Stealth BioTherapeutics, The Corpus, Vifor Pharma and WebMD Global LLC; and serves as co-founder \& non-executive director of Us2.ai. X. Jin, Y.M. Hummel, W.T. Tay, J.F. Nauta, N.S.S. Bamadhaj, J.P. van Melle, A.A. Voors and E.S. Hoendermis declare that they have no competing interests.

Open Access This article is licensed under a Creative Commons Attribution 4.0 International License, which permits use, sharing, adaptation, distribution and reproduction in any medium or format, as long as you give appropriate credit to the original author(s) and the source, provide a link to the Creative Commons licence, and indicate if changes were made. The images or other third party material in this article are included in the article's Creative Commons licence, unless indicated otherwise in a credit line to the material. If material is not included in the article's Creative Commons licence and your intended use is not permitted by statutory regulation or exceeds the permitted use, you will need to obtain permission directly from the copyright holder. To view a copy of this licence, visit http://creativecommons.org/licenses/by/4.0/.

\section{References}

1. Geva T, Martins JD, Wald RM. Atrial septal defects. Lancet. 2014;383:1921-32.

2. Mas JL, Derumeaux G, Guillon B, et al. Patent foramen ovale closure or anticoagulation vs. antiplatelets after stroke. NEngl J Med. 2017;377:1011-21.

3. Masutani S, Senzaki H. Left ventricular function in adult patients with atrial septal defect: implication for development of heart failure after transcatheter closure. J Card Fail. 2011;17:957-63.

4. Silvestry FE, Cohen MS, Armsby LB, et al. Guidelines for the echocardiographic assessment of atrial septal defect and patent foramen ovale: from the American Society of Echocardiography and Society for Cardiac Angiography and Interventions. JAm Soc Echocardiogr. 2015;28:910-58.

5. KhanAA, TanJL, LiW, etal. Theimpact of transcatheter atrial septal defect closure in the older population. A prospective study. JACC Cardiovasc Interv. 2010;3:276-81.

6. Nyboe C, KarunanithiZ, Nielsen-KudskJE, et al. Long-term mortality in patients with atrial septal defect: a nationwide cohort-study. Eur Heart J. 2018;39:993-8.

7. Villablanca PA, Briston DA, Rodés-Cabau J, et al. Treatment options for the closure of secundum atrial septal defects: a systematic review and meta-analysis. Int J Cardiol. 2017;241:149-55.

8. Hasenfuß G, Hayward C, Burkhoff D, et al. A transcatheter intracardiac shunt device for heart failure with preserved ejection fraction (REDUCE LAP-HF): a multicentre, openlabel, single-arm, phase 1 trial. Lancet. 2016;387:1298-304.

9. Baumgartner H, Bonhoeffer P, De Groot NMS, et al. ESC Guidelines for the management of grown-up congenital heart disease. Eur Heart J. 2010;31:2915-57.

10. Lang RM, Badano LP, Mor-Avi V, et al. Recommendations for cardiac chamber quantification by echocardiography in adults: an update from the American Society of Echocardiography and the European Association of Cardiovascular Imaging. Eur Heart J Cardiovasc Imaging. 2015;16:233-70.

11. Wu ET, Akagi T, Taniguchi M, et al. Differences in right and left ventricular remodeling after transcatheter closure of atrial septal defect among adults. Catheter Cardiovasc Interv. 2007;69:866-71.

12. Stephensen SS, Ostenfeld E, Kutty S, et al. Transcatheter closure of atrial septal defect in adults: time-course of atrial and ventricular remodeling and effects on exercisecapacity. Int J Cardiovasc Imaging. 2019;35:2077-84.

13. Schoen SP, Kittner T, Bohl S, et al. Transcatheter closure of atrial septal defects improves right ventricular volume, mass, function, pulmonary pressure, and functional class: a magnetic resonance imaging study. Heart. 2006;92:821-6.

14. Jategaonkar SR, Scholtz W, Butz T, et al. Two-dimensional strain and strain rate imaging of the right ventricle in adult patients before and after percutaneous closure of atrial septal defects. Eur JEchocardiogr. 2009;10:499-502.

15. Lam CSP, Voors AA, De Boer RA, et al. Heart failure with preserved ejection fraction: from mechanisms to therapies. Eur Heart J. 2018;39:2780-92.

16. Kaye DM, Petrie MC, McKenzie S, et al. Impact of an interatrial shunt device on survival and heart failure hospitalization in patients with preserved ejection fraction. ESC Heart Fail. 2019;6:62-9.

17. Søndergaard L, Reddy V, Kaye D, et al. Transcatheter treatment of heart failure with preserved or mildly reduced ejection fraction using a novel interatrial implant to lower left atrial pressure. Eur J Heart Fail. 2014;16:796-801.

18. Hasenfuss G, Gustafsson F, Kaye D, et al. Rationale and design of the reduce elevated left atrial pressure in patients 
with heart failure (reduce LAP-HF) trial. J Card Fail. 2015;21:594-600.

19. Feldman T, Mauri L, Kahwash R, et al. Transcatheter interatrial shunt device for the treatment of heart failure with preserved ejection fraction (REDUCELAP-HFi [reduce elevated left atrial pressure in patients with heart failure]): a phase 2, randomized, sham-controlled trial. Circulation. 2018;137:364-75.

20. Shah SJ, Feldman T, Ricciardi MJ, et al. One-year safety and clinical outcomes of a transcatheter Interatrial shunt device for the treatment of heart failure with preserved ejection fraction in the reduce elevated left atrial pressure in patients with heart failure (REDUCE LAP-HF I) trial: a randomized clinical trial. JAMACardiol. 2018;3:968-77.

21. Ewert P, Berger F, Nagdyman N, et al. Masked left ventricular restriction in elderly patients with atrial septal defects: a contraindication for closure? Catheter Cardiovasc Interv. 2001;52:177-80.

22. Schubert S, Peters B, Abdul-Khaliq H, et al. Left ventricular conditioning in the elderly patient to prevent congestive heart failure after transcatheter closure of atrial septal defect. Catheter Cardiovasc Interv. 2005;64:333-7.
23. NautaJF,HummelYM, van der Meer P, et al. Correlation with invasive left ventricular filling pressures and prognostic relevance of the echocardiographic diastolic parameters used in the 2016 ESC heart failure guidelines and in the 2016 ASE/EACVI recommendations: a systematic review in patients with preserved ejection fraction. Eur J Heart Fail. 2018;20:1303-11.

24. Andersen OS, Smiseth OA, Dokainish H, et al. Estimating left ventricular filling pressure by echocardiography. J Am Coll Cardiol. 2017;69:1937-48.

25. Reddy YNV, Obokata M, Egbe A, et al. Left atrial strain and compliance in the diagnostic evaluation of heart failure with preserved ejection fraction. Eur J Heart Fail. 2019;21:891-900.

26. Masutani SMS, Taketazu M, Ishido H, et al. Effects of age on hemodynamic changes after transcatheter closure of atrial septal defect: importance of ventricular diastolic function. Heart Vessels. 2012;27:71-8.

27. Monfredi O, Luckie M, Mirjafari H, et al. Percutaneous device closure of atrial septal defect results in very early and sustained changes of right and left heart function. Int J Cardiol. 2013;167:1578-84. 